International Journal of Social Science And Human Research

ISSN(print): 2644-0679, ISSN(online): 2644-0695

Volume 04 Issue 11 November 2021

DOI: 10.47191/ijsshr/v4-i11-39, Impact factor-5.586

Page No: 3349-3355

\title{
Crisis Management in Education: A Comparative Study of Handilng Covid 19 in a Speecial Needs and a Standaridise School in Greece
}

\author{
Sofia Tsagdi ${ }^{1}$, Vassiliki Tsipopoulou ${ }^{2}$, Maria Balatsou ${ }^{3}$, Kostas Theologou $^{4}$ \\ ${ }^{1,3,4}$ National Technical University of Athens, Greece \\ ${ }^{2}$ University of West Attica, Greece
}

\begin{abstract}
The COVID-19 pandemic is an emergency of an unprecedented scale, bringing new challenges and severe changes in the schools in Greece. The Ministry of education had to guarantee that learning would be safeguarded as well as impose several measures to mitigate the effects of this unfamiliar situation. Different strategies were followed regarding special needs schools and standard schools. The aim of this article is to investigate how satisfactory the measures were considered by parents and teachers of both schools. Moreover, we seek to explore if the trust of the stakeholders of education was increased or whether it was a lost opportunity to enhance trust among parents, teachers, and the Ministry of Education. For the purpose of our study, we delivered questionnaires among the teachers and parents of both schools as well as conducted semi-structured interviews with the headmasters of the school units. Also, a rigorous and extensive study of the orders issued by the Ministry was done. Our article concludes with several points that need to be taken into consideration in moments of crisis and suggestions on what could be done to alleviate problems in similar times of crisis.
\end{abstract}

KEYWORDS: Covid19, Education, Greece, Crisis Management Schools

\section{INTRODUCTION}

In early March 2020, an extremely contagious novel coronavirus, first detected in late 2019 in Wuhan, China, had spread into a global pandemic. Although it is still unclear when COVID-19 began widespread community transmission in Greece, by March 10, 2020, the Greek Ministry of Education had mandated the closure of all schools all over Greece, first for 14 days and expanding that period for 2 months. An act supported by related literature that supports. Although strangely, children are found to be protected from severe or deadly critical infections, they can become the sources of spread, which was the main reason to close the schools worldwide. (Abdulamir, A. S. et al., 2020). Moreover, since as it is argued (Uscher-Pines et al., 2018) promoting and applying social distancing policies in schools may not be effective in hindering the spread of the pandemic. School shutdowns and social isolation were considered obligatory. As a consequence, through a variety of delivery modalities, teaching and learning continued via eclasses and distance learning strategies. Teachers had to design materials and upload them in the e-class to be accessed by students. This necessitated increasing access to technology and broadband internet services to ensure equity and included large-scale efforts to address urban and rural disparities that exist in Greece. Public schools' teachers were faced with an additional challenge as, without federal guidance, it was still unclear what schools/ teachers were required to provide in relation to the federal special education requirements in the time of a pandemic. To provide this guidance, starting by March 12 the Ministry of education started issuing several official statements called "egkyklioi" associated with remote learning and restating the importance of meeting the mandates of the goals of the national in this new remote learning context. However, the measures enforced by governments to contain the highly contagious COVID19 laid bare the deep inequalities that beset education systems around Greece particularly in relation to special needs education. The lockdowns and subsequent closures of educational institutions have amplified the gap between the rich and the poor, and particularly among special needs students. Therefore, for these disadvantaged groups, teachers and schools alone had to find solutions to the problem of how to meet these basic problems and discrepancies that remote learning posed without jeopardizing learning but rather ensuring that even with schools closed learning would not be hindered. This worry was and still is at the forefront of all educators in Greece. Added to this was the fact, that since the government officials responsible to handle the crisis played catch-up to the exponential spread of COVID-19 teachers had no time to prepare for remote learning but also for real-time teaching. As a result, on March 10, 2020, as well as on November 16, 2021, when the schools closed again, teachers were confronted with not only unfamiliar ground but also with several practical issues. Ensuring that students took home the books, etc., needed for study at home, tying up loose ends; e.g., finalizing test results and reports, Staff preparation and training: 


\section{Crisis Management in Education: A Comparative Study of Handilng Covid 19 in a Speecial Needs and a Standaridise School in Greece}

arrangements for safeguarding; division of work between classes; mechanisms for teachers to remain in touch collectively for mutual support; and brief and simple updates on learning, unfamiliar technologies.

Having briefly mentioned all these problems, this paper wishes to focus on the second period of the closing of schools, which was also the longest one. The central objective of this article is to examine the State's response to the needs of special schools and standard schools in Greece. This period was chosen since we believe that this period had the opportunity, bearing in mind the flux of the situation, to be more carefully planned since the summer period could provide the State time to carefully plan the course of action in different foreseen scenarios. It is important to say that perspective presented in this article is based on research conducted in only two schools in Greece that can be a rather restricting sample for many general conclusions to be drawn. Moreover, it is worth mentioning here that in the second lockdown special education schools were not closed. Even though this time the teachers felt more prepared and had been acquainted with distance education practices they were faced with the decision to keep their school units operating and without the use of protective masks.

The article is structured as follows: An outline of all formal directions, practices, and courses of action of the Greek State is briefly presented. Then we examine in detail the clarity and effect in mitigating the effects of the pandemic. In particular, we highlight the fact special schools were not closed while standards schools, although with differences in the time order, were closed. We further discuss the effects of such policies and what were the responses of both parents of the students and teachers working in the same units. Students were excluded from the process due to the several hurdles we would have to overcome to ensure their participation. We conclude our article with practical suggestions made by the teachers and headmasters of the schools in the case that we feel could help alleviate problems in similar situations.

\section{STATE LEGAL ACTION AND PRACTICES FOR COVID19 IN PRIMARY EDUCATION}

During the summer the Ministry of education-focused its efforts on preparing for the second wave of the pandemic of COVID 19. They issued notes and state orders on how to deal with the forthcoming situation. The orders, while should have aimed at offering pragmatic guidance to teachers, institutional heads, and state officials who were to manage the educational consequences of this crisis, they addressed general preparations that schools should make. Not clear measures and practices were given. Taking into consideration the great differences among school buildings, student numbers, different needs of schools around Greece the official orders were quite vague and allowed for different interpretations and courses of action among schools. Several steps for online learning were done during the summer months. Online platforms were bought designed and ready to be used. Unfortunately, though teachers were not trained beforehand on how to use them or on how to design online lessons using online tools. Resulting in great frustration when they were asked almost overnight to respond to this teaching method, adjusting their teaching material and designing new lessons in the course of the school year. The chance of assisting teachers in being proactive in this period and to find a possible solution to communicate and reach out to students was subsequently lost.

Imposing the use of masks around school premises was a measure that although took time to carefully plan, since funds were given in order to provide all students with masks, still it required many more federal orders in as to be obligatory imposed and respected particularly by parents. It can be marked through while studying the general guidelines that the Ministry issued that due to the different needs of students at different levels that the orders were vague decisions were weak thus requiring more than a few times to be clarified and more carefully worded. Scientific information or scientific consensus on COVID 19 potential as a threat in Education and to students was not clear. Thus it seems that the federal, as well as territory orders, were following policy strategy of 'let science be the guide'. If one, however, extrapolates from the way in which science has worked in similar crisis management situations such as the BSE case (Jacob 2000) or similar ones, one would have to assume that policy decisions would have to be made in anticipation of scientific evidence rather than as a result of them. This is not an unusual situation for policymakers in the Ministry of Education. In fact evidence from other instances where scientific uncertainty was an issue policymaking show that there are at least two general directives. These are: I seek scientific advice, and I do nothing until a reasonable degree of scientific consensus emerges. These directives are at first sight simple and unambiguous. When subjected to closer scrutiny, one begins to see that this simplicity vanishes the moment one has to translate the directives into practice. At this point, it becomes clear that for such principles to work, policymakers would need to have a kind of cognitive frame of reference as well as a set of institutional practices that would help them to operationalise these directives. Hence these weak policies and decisions created more anxiety to educators who demanded more provisions and clearer order on the course of action. One particular order that called for the criticism among educators was the closing of classes if a student was sick with COVID 19 and not the whole school. The main challenge reported was that it would be difficult to reassure that the students that would be torn away from their social group and would be switched to synchronous learning through online platforms would be worried about suffering a disadvantage compared to their peers that would continue in school. Several more challenges regarding school meals, distances in the school playground, siblings in other classes, the inequalities sharpening between students richer students equipped with technology to participate in synchronous learning, were difficult ambiguous and let on the schools to decide and to implement. This unclear situation had left thousands of teachers, feeling left in the lurch. While this was the case in normal schools in Greece special needs schools were even more challenging. According 


\section{Crisis Management in Education: A Comparative Study of Handilng Covid 19 in a Speecial Needs and a Standaridise School in Greece}

to educational law concerning special education equal opportunities should be provided to the general student population as well as special needs students. This also must be applied during a school closure [i.e., by providing online learning], the school must ensure that students with disabilities also have equal access to the same opportunities, including the provision of free appropriate public education. Here lies a serious misunderstanding that circulated within Ministry officials. Ministry officials interpreted this to mean that schools could not offer remote learning opportunities for any students due to their perceived inability to meet the requirement of it. Also that the special needs students should be excluded from the measure of wearing a mask, which increased special needs teachers' fear and anxiety. As a result, fearing that if the school units closed numerous public school students with and without disabilities were not receiving any educational services the officials decided to let special needs schools open during the pandemic. This decision prompted a great discussion and dissatisfaction of special needs educators, who felt that the cornerstone of the nation's special needs educational law, meaning asserting that lessons must be designed to meet the child's unique needs and that prepares the child for further education, employment, and independent living; could be met through the use of online material and platforms as was the case with non-special needs students. A further issue that sparked more distrust and feeling of neglect lies in the fact that the federal decisions sent to schools in the form of "egkykilioi" as mentioned above were not only ambiguous but also in many cases identical with the ones sent to standard schools with just a note for special education to adapt. As a result, these decisions were usually referred to among teachers as "oracles" showing their stress and marginalisation. They claim not to switch special schools to distance online learning adopted by the Ministry's officials though do not have solid grounds in academic literature and research. Research shows that synchronous and asychorous learning can cater to the needs of students provided that it is carefully planned and given the required equipment and guidance (ADA 1990, Camera 2020).

\section{Research questions}

This study aims to answer to two main research questions:

1) How satisfied were teachers of both schools with the different handing of the COVID crisis by the Greek Ministry of Education?

2) Did teachers' trust in Ministry's actions in handing this or future crisis increased?

\section{METHODOLOGY}

\subsection{Methodology}

Due to the imposed covid-19 movement restrictions and subsequent survey constraints we decided to conduct a mixed-mode methodology survey that included an email administered web survey through google forms and a telephone survey for specific parts of the targeted population, such parents with special needs or with lower education that were unable to respond by a different mode and would otherwise have been excluded from the sample population (S.C.Ratzan_ 1982). The mad cow crisis: Health and the public good. Journal of hazardous materials.

Choosing this tailored to the particular pandemic situation, mixed-mode survey design, allowed us not only to minimize coverage error but helped us improve timeliness and response rates.

Having per vim (et virtue) excluded the face-to-face interviews, also meant that we were able to minimize the extremeness of responses that have often been found in aural modes (Christian,2007) due to interviewer personal characteristics or bias such as social desirability or acquiescence phenomena that consistently account for measurement errors. Opting for a mixed-mode survey empowered us to take advantage of the strengths of a certain mode and overcome the weakness of another, in order to minimize total survey error as much as possible within resource and time constraints.

Setting up a web survey, allowed for more design flexibility, resulting in lower costs, and mitigated the risk of social norms to be evoked in ways that would impact measurement in our survey. In particular, it alleviated the social desirability bias, the tendency to give answers in a manner that will be viewed favorably by the person asking the questions, and the deeply embedded, especially in the public sector, tendency to agree with someone rather than disagree (acquiescence).

We also decided to structure questions similarly across both survey modes (telephone and google forms), aiming at improving data quality and overcoming differences in how people process visual and aural modes of communication.

According to the cognitive model of response order effects in survey measurement (Schwarz, Hippler, Noelle-Neumann,1992), in self-administered visual web surveys, respondents are more likely to be influenced by items appearing early in lists. Moving through more possible answers in the list, respondents' attention span is narrowing and they are less able to remember alternative answers. Thus, if early response options are logical and convincing, they are more likely to be endorsed, resulting in primacy effects (Ansari \& Mela, 2003; Dreze \& Zufryden, 2004; Hofacker \& Murphy, 200.). On the other hand, in interviewer-administered telephone surveys, there is typically not enough time for respondents to process all the responses as they are read by the interviewer. Consequently, the last answers are usually more likely to be remembered and chosen, resulting in recent effects ( Moore,1997). Deciding to have certain respondents of the same target population choosing to give their answers either way, through the telephone 


\section{Crisis Management in Education: A Comparative Study of Handilng Covid 19 in a Speecial Needs and a Standaridise} School in Greece

with the presence of an interviewer or through self-administered online tools, allowed us to reduce measurement error, and resulted in more survey responses. Most importantly, it created the potential for synergy between contacts via different modes.

\subsection{Sample}

One of the first key decisions in sampling is determining the required sample size. What is an appropriate sample size is usually determined by i) the size of the sampling population and how much variation there is on its characteristics of interest ii) the desired level of confidence one wishes to have in the estimates and iii) the desired margin of sampling error.

In order to deduct our required size sample for our study we use the formula by Survey System, 2010:

Where,

$$
s s=\frac{z^{2} * p(1-p)}{c^{2}}
$$

$\mathrm{ss}=$ is the completed sample size needed for the desired level of precision

$\mathrm{z}=$ the critical value for the desired level of confidence (1.96 for $95 \%$ level of confidence)

$\mathrm{p}=$ the proportion being tested

$\mathrm{c}=$ the desired margin of sampling error $(0,07= \pm 7)$

Applying this formula, the completed sample size is 196.

However, when populations, like the one in our study, are small, researchers usually adjust this formula by including the Finite Population Correction (FPC), which accounts for the size of the target population in the calculation. The FPC adjusts for the fact that in smaller populations, a given sample provides proportionately more information than a sample of the same size in larger populations.

Following the finite population correction formula, we calculated the new ss:

new $s s=$ ss $/ 1+($ ss- 1$) /$ pop

where pop $=200$

and the estimated new sample size needed for our study is 49 .

\subsection{Target population}

Our target population was the parents and educators of two schools. A normal school in the suburbs of Athens, Greece and a special school in Athens. Also, a semi-formal interview with the headmasters of the school was conducted in order to clarify points and enter into a deep discussion of issues that they themselves wanted to initiate.

\subsection{Questionnaires}

The questionnaires used Likert scales rated from one to seven. With one being the lowest mark and seven the highest mark in the questions of satisfaction and trust. The two questionnaires administered to parents and educators included 10 questions aiming to unravel the degree of satisfaction and trust participants had to the Ministry's response to the COVID 19 pandemic in education. The questions were aimed at whether participants were reassured and on whether the Ministry meet through its actions meet its legal obligations and maintain the rights of students and families during a time of significant change.

\subsection{Expert reviews}

In order to diagnose and solve problems before our survey went into the field, two high esteemed academics were asked to review the draft questionnaire that we would administer by the telephone or the web. The chosen experts not only reviewed the translation of the items of the initial scales but thoroughly examined the structure of the questions, the response alternatives, the instructions given to respondents for answering the questions, and the order of the questions themselves. More sensitive questions regarding employees' interactions with politicians were placed at the end of the questionnaire and technical questions from the Common Assessment Framework where respondents were unlikely to know the answer, were dropped. The basic concept behind any changes that were made, was that all questions should be understood in the same way by all respondents, especially questions that were common for the two target populations, employees and citizens/recipients of services.

\subsection{Pretesting, feedback from respondents, outlier detection, and questionnaire validation.}

The goal of the pretesting was to determine whether the proposed questionnaire and procedures to be adopted would be adequate for the larger study. The questionnaire was tested in both modes that respondents would use in order to complete it so that we could see how respondents would be able to navigate the questionnaire without assistance in the case of the online tool but also to understand if certain items were particularly problematic to administer over the phone and needed further explanation. The pilot testing gave us a sense of how sample members will react to the contacts and material provided and was particularly useful for making estimates of the response rates and seeing if only certain types of people are responding, leading to an increased potential for nonresponse error. In addition, it confirmed the need i) to have telephone interviews for a part of the sample population and ii) to administer the web survey through google forms and not via emails in order to address respondents' data privacy and time concerns. 


\section{Crisis Management in Education: A Comparative Study of Handilng Covid 19 in a Speecial Needs and a Standaridise School in Greece}

After all respondents recruited in the pilot testing provided their answers and most importantly, their comments on the questions included in the draft questionnaire and the data collection method used, we rephrased some questions in order to facilitate test subject understanding and comprehension. We also dropped an item from the citizens' questionnaire that didn't fit the circumstances of respondents. Next, we looked for atypical patterns of responses (outlier detection) but no out-of-range values or items with little variance were found. At this stage, the final version of the questionnaire was confirmed.

\section{RESULTS}

Concerning the educators of both schools it is clear from the questionnaires that the level of satisfaction and trust in decisions officials took to safeguard the students and their own safety is indicatively low.

Out of the 60 educators in total that participated in the survey, both from special needs and standardize school, the vast of whom majority maintain their clear dissatisfaction with the clarity of the measures that were called to implement. The scores numbers are indicative low in this question

Furthermore, they stated a high level of dissatisfaction with the rate they were informed about the new changes and measures. The scores given to the question of clarity of measures was low by teachers. In the interview the headmasters reported that the measures were vague leaving it to the board of teachers to decide based on the school units different characteristics and needs. This however, intensified the feeling of insecurity to teachers who felt alone to decide on issues they lack knowledge and expertise to do so.

It is not questionable based on these facts that educators of the general school were satisfied and relieved when a general school shutdown was announced, in terms of their safety while really worried for the continuation of their teaching through the use of online platforms. Also, it becomes evident that simultaneously the educators of the special needs school felt even more dissatisfied with the decision, not to close the special needs schools on the grounds that neither synchronous nor asynchronous teaching could cater for the special needs students have. A decision not supported by theory and although welcomed by parents, raised worries and stress to the teachers of the special needs unit. Since no protective masks were worn by special needs students, teachers felt that their wellbeing was neglected that affected their job performance. Their levels of distrust and even anger were reported in the study at a very high level.

Regarding the second research question our article adressed: trust. Teachers of both schools reported feelings of distrust. They reported that they felt not heard, their notes although asked were not eventually considered. This added to their mis trust making them believe that in a future crisis same chaotic conditions would occur, since there is no provision or action to carefully plan and draw knowledge from current practices. This trend can be also seen by the reports of the teachers association and boards all over Greece that have published widely showing their disatisfaction and calling their colleagues to take action against future unorganised actions by the State throwing the problem back to them rather than trying to work out solutions on their own.

An interesting finding of our research is the discrepancy between the opinions of parents.

Although educators are highly unsatisfied and their trust level in the decisions and the measures of the government significantly low. This is not the case for the parents of both groups. The parents appear satisfied with the decisions of the Ministry of Education and their trust in the services and course of action the Ministry followed is increased. We believe this was due to the fact that the felt that teachers did what was humanly possible to meet the demands of their work and that raised also trust not only to teachers but also to the Ministry that as the parents reported reacted immediately and effectively in order to safeguard that teaching will take place.

\section{CONCLUSION}

In these circumstances, education was affected greatly as one main daily activity of millions of students, teachers, and parents around the world (ETF, 2020; Hopegood; 2020; OECD, 2020; UNESCO, 2020). In most countries, schools are closed and education is provided through distance education platforms (Reimers, 2020). It is a challenging situation for both teachers, students, and parents around the world with the most vulnerable groups faced with even more obstacles than ever. However, we feel that there are multiple strategies that may help to ensure that students' legal rights are met. It is essential to give careful attention to the special needs of each school unit so as to address its needs and allow for feasible solutions. For example, giving more school classes in public buildings around the school areas so as to ensure social distancing, particularly in highly populated school units.

Another strategy would be to plan and arrange free internet access to students as well as provide laptops or tablets so as to ensure that students can participate in the online courses. This could have helped avoid issues of affordability, especially in unprivileged areas where internet access remains a luxury. Parallel to this, institutions and educators had to equip themselves with the necessary tools and skills at a staggering speed to shift to remote learning. But, a large number of educators and special needs teachers in Greece lack sophisticated technology and experience in designing online learning environments Moreover, we believe that supporting the Professional Development of Teachers via Distance Education before schools open so as to have educators prepared andtrained to ensure that they can cope with the needs of online teaching. Finally, help in establishing authentic partnerships with 


\section{Crisis Management in Education: A Comparative Study of Handilng Covid 19 in a Speecial Needs and a Standaridise School in Greece}

families extended beyond sending home materials or messaging to families. These partnerships could promote parents, caregivers, and community members as equal participants in the educational process, with shared and meaningful responsibilities. As result, reassurance of the parents and teachers could be achieved. Many teachers and counsellors could provide this reassurance without direct instruction from examining bodies and institutions about the arrangements with frequent communication on educational and administrative matters. Hence, parents and students in deprived situations anxieties would be assured.

The two headmasters schools identified the lack of practical measures when the schools opened, as a primary factor that caused anxiety and mistrust among teachers, parents, students and the larger community. They maintained that in other European countries measures were more targeted and carefully planned and administered. Teachers were aware of these measures in other countries and this exacerbated their feelings of neglect and inferiority. Also, another strategy would be to change educational supports and services to ensure that vulnerable populations and communities are not put at even more of an increased risk for the community transmission of COVID-19. Educators asked for comprehensive Covid-19 protocols even at the time when the scientific evidence was inconclusive. The policy of policy 'wait and see' attitude based on halting further intervention until more evidence is available was considered as too risky and potentially costly to the general public since it halts immediate intervention. This paper concludes with the case of COVID 19 crisis management as a good example of how even good policy principles may be thwarted by bad policy design and implementation.

\section{REFERENCES}

1) Ansari, A., \& Mela, C. F. (2003). E-customization. Journal of Marketing Research, 40(May), 131-145.

2) Ratzan, S.C., (Ed.), (1998). The mad cow crisis: Health and the public good. UCL Press.

3) Jacob, M., Hellstrom, T., (2000). Policy understanding of science, public trust and the

4) BSE-CJD crisis. Journal of Hazardous Materials, 78(2), 303-317. Retrieved from www.elsevier.nlrlocaterjhazma

5) Archambault, L. and Crippen, K. (2009). K-12 distance educators at work: Who's teaching online across the United States, Journal of Research on Technology in Education, 41(4), 363-391. Retrieved from https://doi.org/10.1080/15391523.2009.10782535

6) Uscher-Pines, L., et al. (2018). School practices to promote social distancing in K-12 schools: Review of influenza pandemic policies and practices. BMC Public Health. BMC Public Health, 18(1), 1-13. Retrieved from https://doi.org/10.1186/s12889-018-5302-3

7) Americans With Disabilities Act of 1990, Pub. L. No. 101-336, 104 Stat. 328 (1990).

8) Camera, L. (2020, April 15). Schools struggle to educate students with disabilities amid pandemic. U.S. News and World Report. Retrieved from https://www.usnews.com/news/education-news/articles/2020-04-15/schools-struggle-to-educatestudents-withdisabilities-amid-pandemic

9) Christian, L. M. 2007. "How Mixed-Mode Surveys Are Transforming Social Research: The Influence of Survey Mode on Measurement in Web and Telephone Surveys." Ph.D. dissertation, Washington State University, Pullman, WA.

10) Drèze, X. and Zufryden, F. (2004) Measurement of Online Visibility and its Impact on Internet Traffic. Journal of Interactive Marketing, 18, 1, 20-37

11) Hofacker, C. F., \& Murphy, J. (2005). Using server log files and online experiments to enhance internet marketing. In S. Krishnamurthy (Ed.), Contemporary research in e-marketing (Vol. 1, pp. 226-249). Hershey, PA: Idea Group

12) Hopegood, S. (2020). Coronavirus: Our principles, values, and shared humanity. Worlds of Education. Retrieved from https://www.worldsofeducation.org/en/woe_homepage/woe_detail/16719/\%C2\%AB-coronavirus-nos-principes-nosvaleurs-et-notrehumanit\%

13) Stern, M. J., Adams, AE. (2009). Digital inequality and place: The effects of technological diffusion on Internet proficiency and usage across rural, suburban, and urban counties. Sociological Inquiry 79(4), 391-417.

14) Setiawan, A. R. (2020). Scientific literacy worksheets for distance learning in the topic of Coronavirus 2019 (COVID-19). EdArXiv. DOI: https://doi. org/10.35542/osf. io/swjmk

15) Krosnick, J.A., \& Alwin, D. (1987). An evaluation of a cognitive theory of response-order effects in survey measurement. The Public Opinion Quarterly, 51(2), 201-219. https://doi.org/ 10.1086/269029

16) Moore, D. (1997). New Pedagogy and New Content: The Case of Statistics. Internufionul Sfutisticul Review, 65. 123-165

17) Ratzan, R. M. (1982). On teachers

18) Reimers, F., Schleicher, A., Saavedra, J., \& Tuominen, S. (2020). Supporting the continuation of teaching and learning during the COVID-19 Pandemic. Oecd, 1(1), 1-38

19) Schleicher, A. (2020). The impact of COVID-19 on education insights from education at a glance 2020. Retrieved from oecd. org website: https://www. oecd. org/education/the-impact-of-covid-19-on-education-insights-education-at-a-glance2020. $p d f$. 
Crisis Management in Education: A Comparative Study of Handilng Covid 19 in a Speecial Needs and a Standaridise School in Greece

20) Schwarz N, Hippler HJ, Noelle-Neumann E. 1992. A cognitive model of response-order effects in survey measurement. In Context Effects in Social and Psychological Research, ed. N Schwarz, S Sudman, pp. 187- 201. New York: SpringerVerlag 